\title{
Freshness-Lowering Rates of Cod and Sea Bream Viewed from Changes in Bacterial Count, Total Volatile Base- and Trimethylamine- Nitrogen, and ATP Related Compounds*1
}

\author{
Shigeo EHIRA*2 and Hitoshi UCHIYAMA*2 \\ (Received January 16, 1974)
}

\begin{abstract}
It has been known experientially that the rate of freshness-lowering of fish varies markedly between species: that of cod being quite rapid and that of sea bream slow. These fish species were stored in ice and changes in bacterial count, TVB-N, TMA-N, ATP related compounds and $\mathrm{K}$ value of their muscle were examined in relation to their freshnesslowering rates and initial spoilage. Determination of ATP related compounds was performed using an autoanalyzer by a concave gradient method. The results obtained are as follows;

Using AG $1 \times 4$, $\mathrm{Cl}^{-}$type, $200-400$ mesh, ATP related compounds were automatically separated in about $70 \mathrm{~min}$. The time from death to the onset of initial spoilage differed considerably between cod and sea bream. IMP in cod muscle dropped remarkably within two days of ice storage, whereas that of sea bream persisted to some extent even after 16 days. Consequently, with regard to $\mathrm{K}$ value, there was also a striking difference between cod and sea bream. The rate of IMP decomposition in Japanese red bream muscle was changed little by mixing it with an aqueous extract of Alaska pollack muscle, or the muscle itself. Changes in ATP related compounds in the muscles and the $K$ values coincided with the freshness-lowering of fish. It was concluded that the $\mathrm{K}$ value could be used as one means of evaluating the freshness of fish.
\end{abstract}

SArTo et al. ${ }^{1}$ proposed a method for determination of freshness of fish using $\mathrm{K}$ value which is defined as the ratio of the sum of $\mathrm{HxR}$ and $\mathrm{Hx}$ to the total amount of ATP and its related compounds. The authors ${ }^{2-6)}$ confirmed the usefulness of $\mathrm{K}$ value and concluded that not the $\mathrm{Hx}$ test proposed by JONES et al., ${ }^{7,8)}$ but $\mathrm{K}$ value must be employed for estimating freshness of fish, because, as reported previously, ${ }^{6}$ little $\mathrm{Hx}$ was formed in muscle of the species such as horse-mackerel, mackerel, tunas, and many others during ice storage. In Japan, there are many kinds of commercially important fishes, and the freshness-lowering rate is experientially known to vary considerably between species. Therefore, for practical use of $\mathrm{K}$ value, it is necessary to elucidate the relations among the experientially known fact, the post-mortem changes in ATP and its related compounds, and the freshness-lowering in the bacteriological sense. And the present study was undertaken, using two kinds each of cod and sea bream whose freshness-lowering rates are experientially known to be fast and slow, respectively. Also, a procedure for

*1 Contribution from Tokai Reg. Fish. Res. Lab., B 580.

*2 Tokai Reg. Fish. Res. Lab., Kachidoki, Chuo-ku, Tokyo (江平重男 - 内当 均: 東海区本研究所) The following abbreviations are used: ATP, ADP, and AMP; adenosine 5'-tri-, di-, and monophosphate, respectively, IMP; inosine 5 '-monophosphate, $\mathrm{HxR}$; inosine, $\mathrm{Hx}$; hypoxanthine, TVB-N; total volatile base-nitrogen, TMA-N; trimethylamine-nitrogen. 
the assay of ATP related compounds in fish muscle by an autoanalyzer was studied employing a concave gradient elution system.

\section{Materials and Methods}

Fish Pacific cod Gadus morrhua macrocephalus and Alaska pollack Theragra chalcogramma, caught by long line off Rebun Island, Hokkaido, were used throughout the work. A portion of anterio-dorsal muscle (about $10 \mathrm{~g}$ ) was removed and dry-iced. The fish specimens whose dissected part was covered with polyethylene film disinfected with alcohol, were placed in a polyethylene bag, stored in melting ice, and brought back to Wakkanai Fisheries Experimental Station, Hokkaido. Rigor mortis occurred $16 \mathrm{hr}$ after being caught. The fish specimens were handled so as to prevent bacterial contamination by alcoholic disinfection of instruments such as scalpel, pincette, etc. and the dissected part of the fish.

Japanese red bream Pagrus major and Japanese black bream Mylio macrocephalus were obtained at Arasaki Branch of Tokai Regional Fisheries Research Laboratory. After being held in a sea water aquarium for 3 days after catch, the fish were killed by cutting hindbrain. A portion of anterio-dorsal muscle was removed and dry-iced and the fish were iced in the same way as with Pacific cod and Alaska pollack.

Reagents ATP, ADP, AMP, IMP, HxR and Hx were the best available from Sigma, Boehringer \& Soehne or Ajinomoto. All the chemicals other than Hx which was dissolved in $0.05 \mathrm{~N}$ sodium hydroxide, were dissolved in water, and $10 \mathrm{~mm}$ stock solutions were prepared.

Measurement of bacterial count in fish muscle Number of colonies formed on the surface of nutrient agar (Nippon Eiyokagaku Co.), after being incubated at $25^{\circ} \mathrm{C}$ for $48 \mathrm{hr}$ was examined. The results were given in terms of the bacterial count per $\mathrm{g}$ of muscle.

Determination of TVB-N TVB-N in fish muscle was determined by a ConwAY's method.9 ${ }^{9 !}$

Determination of TMA-N TMA-N in fish muscle was determined by a CoNwAY's method $^{9 !}$ and by the picrate method as modified by HASHIMoro et al. ${ }^{10)}$

Preparation of aqueous extract of muscle Alaska pollack muscle was homogenized with approximately 3 volumes of deionized water in an ice-chilled blendor (Nihon Seiki Co.) and the homogenate was centrifuged at $10,000 \times \mathrm{g}$ for $10 \mathrm{~min}$ at $0^{\circ} \mathrm{C}$. In order to remove ATP related compounds, the supernatant was adjusted to $\mathrm{pH} 9.4$ (using thymolblue test paper) with ammonium hydroxide, mixed with Dowex $1 \times 4,200-400$ mesh, stirred and centrifuged. The substances absorbing ultra violet rays were removed thoroughly by this procedure.

Preparation of perchloric acid extract of muscle A portion of the muscle taken from iced fish was extracted with perchloric acid, and neutralized as usual. ${ }^{5}$ In measuring the 
rate of IMP decomposition, $2 \mathrm{~g}$ of dorsal muscle of Japanese red bream was mixed with $1 \mathrm{~m} l$ of the aqueous extract of Alaska pollack muscle prepared as above and $1 \mathrm{~m} l$ of chlortetracyclin (Aureomycin) solution (final concentration: $5 \mathrm{ppm}$ ) and homogenized. Also, $1 \mathrm{~g}$ each of Japanese red bream and Alaska pollack muscle was mixed, homogenized and stored as above. Controls for each species were prepared using $2 \mathrm{~g}$ of its own muscle and $2 \mathrm{ml}$ of the chlortetracyclin solution in the same way as described above. A series of homogenates in homogenizer cups were held in melting ice, and one sample each was taken from them at appropriate intervals, extracted with perchloric acid and neutralized with potassium hydroxide.

Analysis of ATP related compounds by autoanalyzer A Hitachi Multipurpose Liquid Chromatograph model 034 was used. As shown in Fig. 1, the autoanalyzer consists of

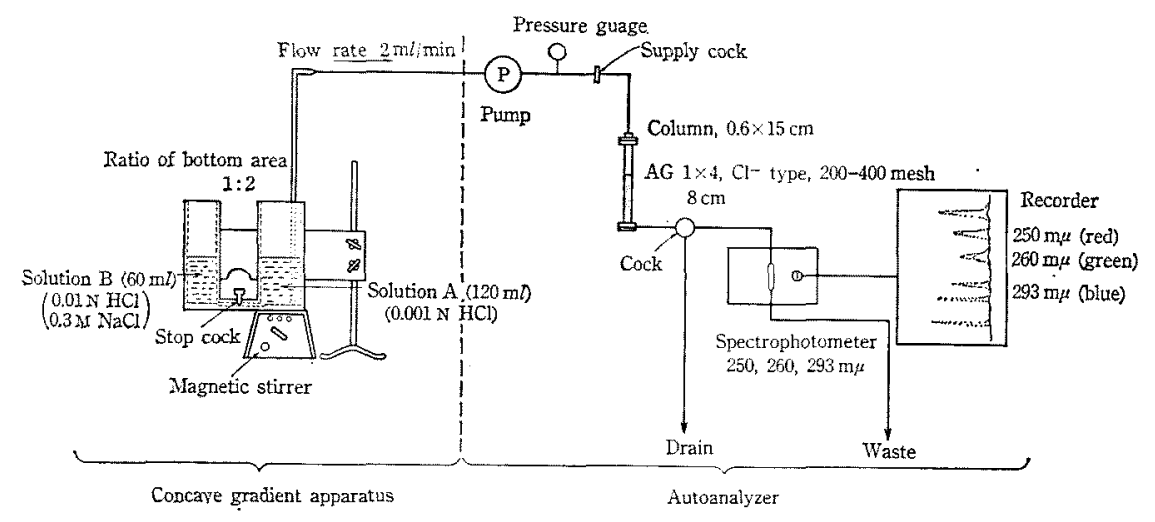

Fig. 1. Schematic view of autoanalyzer.

a constant-flow-rate pump, a column, a spectrophotometer and a recorder. ATP related compounds were analyzed by using the autoanalyzer and an apparatus for concave gradient elution system described previously.5) A method reported previously was modified as follows;

AG $1 \times 4, \mathrm{Cl}^{-}$type, 200-400 mesh (Bio Rad Co.) was packed in a $0.6 \times 15 \mathrm{~cm}$ column in $8 \mathrm{~cm}$ high. To the column $0.4 \mu$ moles each of authentic ATP and its related compounds or the extract equivalent to $0.1 \mathrm{~g}$ muscle was applied. In the cylinders of the concentration gradient apparatus, $120 \mathrm{~m} l$ of solution $\mathrm{A}(0.001 \mathrm{~N} \mathrm{HCl})$ and $60 \mathrm{~m} l$ of solution $\mathrm{B}$ $(0.01 \mathrm{~N} \mathrm{HCl}$ containing $0.3 \mathrm{M} \mathrm{NaCl})$ were taken. ATP related compounds were eluted at a flow rate of $2 \mathrm{~m} l$ per min using the constant-flow-rate pump. About $13 \mathrm{~min}$ after initiating elution, HxR and $\mathrm{Hx}$ fraction appeared, followed by AMP, IMP, ADP and ATP in this order. With the gradient-eluting solution described above, it takes too long a time to fractionate ATP. In order to shorten the time, the gradient-eluting solution 
was replaced, after the peak of IMP was recorded, with solution $\mathrm{C}(0.01 \mathrm{~N} \mathrm{HCl}$ containing $0.8 \mathrm{M} \mathrm{NaCl}$ ), in which the concentration of sodium chloride was much higher than solution B. Absorbances at 250, 260 and $293 \mathrm{~m} \mu$ of each fraction were recorded automatically with different colours. The content of each constituent was calculated by the HW method. ${ }^{11}$

It has been clarified that ATP decomposes post-mortem in fish muscle by the following pathway: $\left.{ }^{12-14}\right) \quad \mathrm{ATP} \rightarrow \mathrm{ADP} \rightarrow \mathrm{AMP} \rightarrow \mathrm{IMP} \rightarrow \mathrm{HxR} \rightarrow \mathrm{Hx}$. From the amounts of respective compounds determined as above, $K$ value can be calculated, though $H x R$ and $\mathrm{Hx}$ are not separated from each other. When separation of $\mathrm{HxR}$ and $\mathrm{Hx}$ is required, $1 \mathrm{ml}$ of saturated sodium borate solution is added to $1 \mathrm{ml}$ of the sample solution to derive HXR into a borate complex. ${ }^{15,16)}$ Owing to an increased affinity of the complex to the resin, HxR and $\mathrm{Hx}$ are easily separated. The resin column was equilibrated for about 20 min with a sodium borate solution which was prepared by mixing $100 \mathrm{ml}$ of $0.1 \mathrm{M}$ $\mathrm{Na}_{2} \mathrm{~B}_{4} \mathrm{O}_{7}, 180 \mathrm{ml}$ of $0.1 \mathrm{M} \mathrm{HCl}$ and $80 \mathrm{~m} l$ of $\mathrm{H}_{2} \mathrm{O}$ and adjusting to $\mathrm{pH} 7.75$ with $\mathrm{HCl}$, and loaded with an aliquot of the sample solution. By a concave gradient formed by using solutions $\mathrm{A}$ and $\mathrm{B}$, all the compounds from $\mathrm{Hx}$ to ATP were fractionated. As described above, the eluting solution was replaced with solution $C$ when the peak of IMP was recorded.

\section{Results and Discussion}

Fractionation of ATP related compounds by autoanalyzer Figs. 2 and 3 show the column chromatographic patterns of authentic ATP and its related compounds. HxR and $\mathrm{Hx}$ were not separated in the former, but clearly separated in the latter. The time required for the complete separation of all the compounds was about 60 and $70 \mathrm{~min}$, respectively. In the column chromatography using Dowex $1 \times 4, \mathrm{Cl}^{-}$type, $200-400$ mesh, $3 \mathrm{hr}$ were needed, as reported previously. ${ }^{5}$. The shortening of the time required is mainly ascribable to the use of $\mathrm{AG} 1 \times 4,200-400$ mesh. As the chromatographic patterns are recorded with absorbances at 250,260 and $293 \mathrm{~m} \mu$, peaks of $\mathrm{Hx}$, its nucleoside (HxR), its nucleotide (IMP) and adenine nucleotides can be identified roughly from their spectral characteristics: the absorbance at $250 \mathrm{~m} \mu$ is higher than that at $260 \mathrm{~m} \mu$ with the former 3 compounds, and the reverse is true for adenine nucleotides. When HxR and $\mathrm{Hx}$ were separated from each other, $\mathrm{Hx}$ appeared about 12-13 min after initiation of elution, and HxR about 10 min later. As shown in Fig. 3, Hx and HxR were separated completely from each other. For their complete separation, it was found necessary to adjust the $\mathrm{pH}$ of the sodium borate solution which was used for equilibrating the column, exactly to 7.75 , because the formation of inosine-borate complex depends upon the $\mathrm{pH}$. Below pH 7.75, HxR was eluted not only in the position shown in Fig. 3 but also slightly 


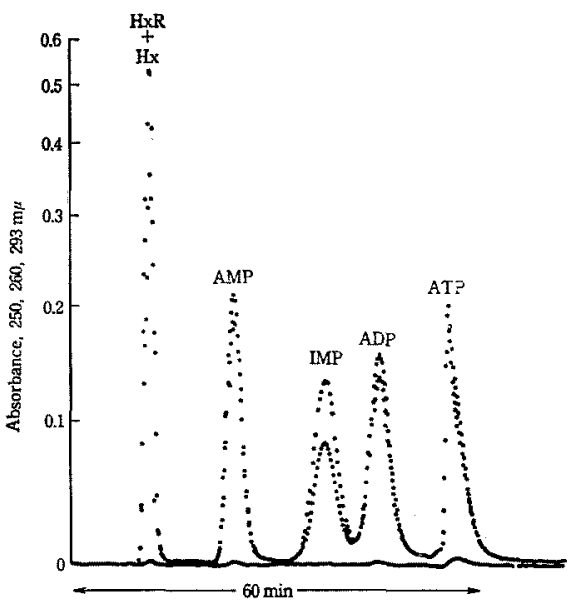

Fig. 2. Automatic separation of authentic Hx + HxR, IMP, AMP, ADP and ATP by liquid chromatograph. A mixture of $0.4 \mu$ moles each of the compounds was separated on $\mathrm{AG} 1 \times 4\left(\mathrm{Cl}^{-}\right.$type $)$ column by concave gradient elution at a flow rate of $2 \mathrm{ml}$ per min.

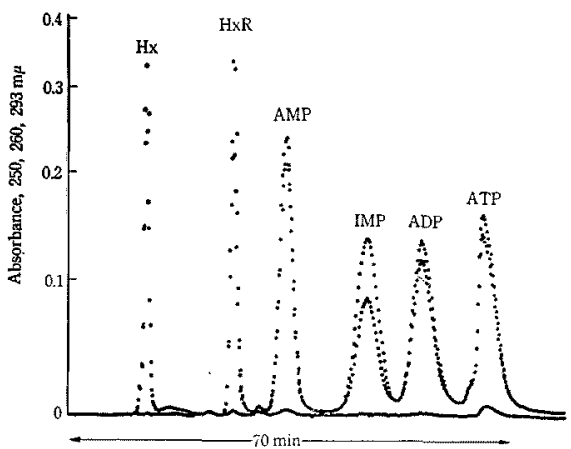

Fig. 3. Automatic separation of authentic Hx, HxR, IMP, AMP, ADP and ATP by liquid chromatograph. A mixture of $0.4 \mu$ moles each of the compounds was separated on $\mathrm{AG} 1 \times 4\left(\mathrm{Cl}^{-}\right.$ type) column by concave gradient elution at a flow rate of $2 \mathrm{ml}$ per min. $\mathrm{HxR}$ and $\mathrm{Hx}$ were separated from each other by treating sample solution with sodium borate.

after $\mathrm{Hx}$, and the former incompletely separated from the latter. This may be ascribable to an incomplete formation of inosine-borate complex. On the other hand, above $\mathrm{pH} 7.75$ the elution of HxR was delayed, resulting in an unsatisfactory separation from AMP.

Changes in bacterial count, TVB-N and TMA-N in fish muscle Fig. 4 shows the changes in bacterial count and TVB-N which have been used generally as indices of freshness of fish, during ice storage. The shift time from the acceleration phase to the logarithmic phase ${ }^{17)}$ of the growth of bacteria in muscle were 4 and 10 days after catch for the cod and bream, respectively. These results are in good agreement with the experientially known fact that the freshness of cod lowers rapidly, and that of sea bream, slowly. In all the 4 species, TVB- $N$ increased roughly in parallel with the growth of bacteria, and did not increase so far as bacterial count remained less than $10^{2}$ per $g$ of muscle. As reported previously, ${ }^{2}$ it can be said safely that this fact suggests that, in the initial stage of ice storage of fish, bacteria are not, or little, concerned with freshness-lowering of fish. Accordingly, TVB-N, which has been used as an index of freshness of fish, does not represent the true freshness described below.

Changes in TMA-N in the fish muscle during ice storage is shown in Fig. 5. TMA-N began to increase sharply 6 days after catch in both cods, while it did, though gradually, 12 days after catch in both breams. There was a rough parallelism in all instances between the bacterial count and TMA-N. As with TVB-N, TMA-N seems to be useful only for estimating the initial spoilage. Considering their accuracies, however, measuring 
TMA-N is preferable to measuring TVB-N, because, differing from TVB-N, the TMA-N content at the time of death is not influenced by the amount of adenine nucleotides. SHEWAN et al. ${ }^{18)}$ made a critical evaluation of picric acid method for estimating TMA,
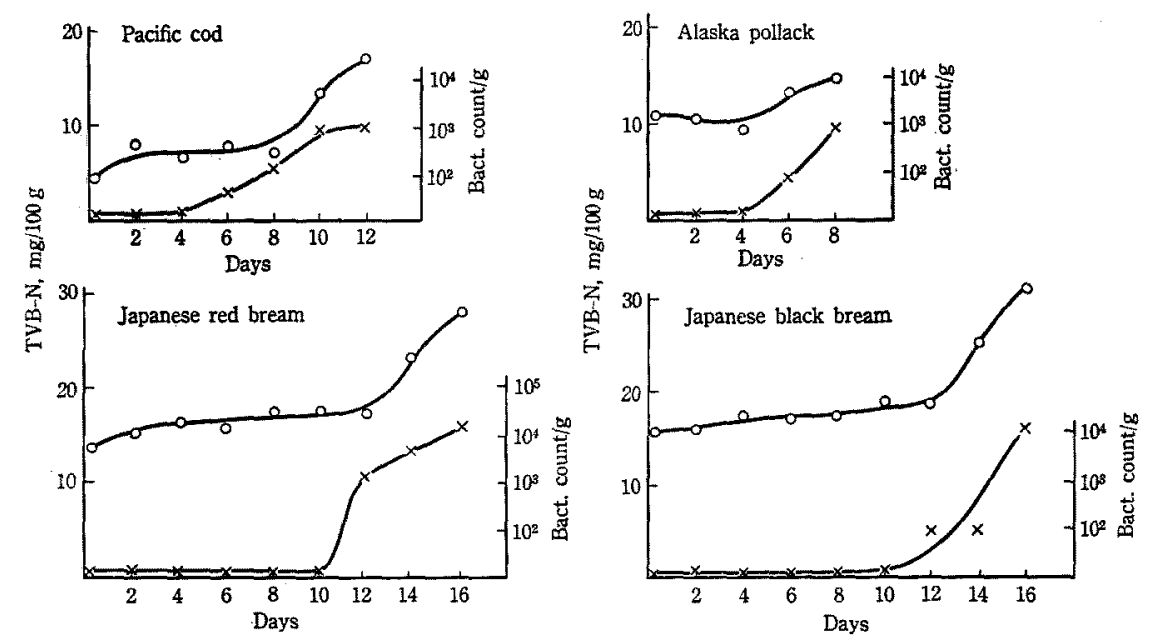

Fig. 4. Changes in the bacterial count, amount of total volatile base (TVB)-N in the muscles of Pacific cod, Alaska pollack, Japanese red and black breams during ice storage, $x-x$ : Bacterial count, $\mathrm{O}-\mathrm{O}$ : TVB-N.
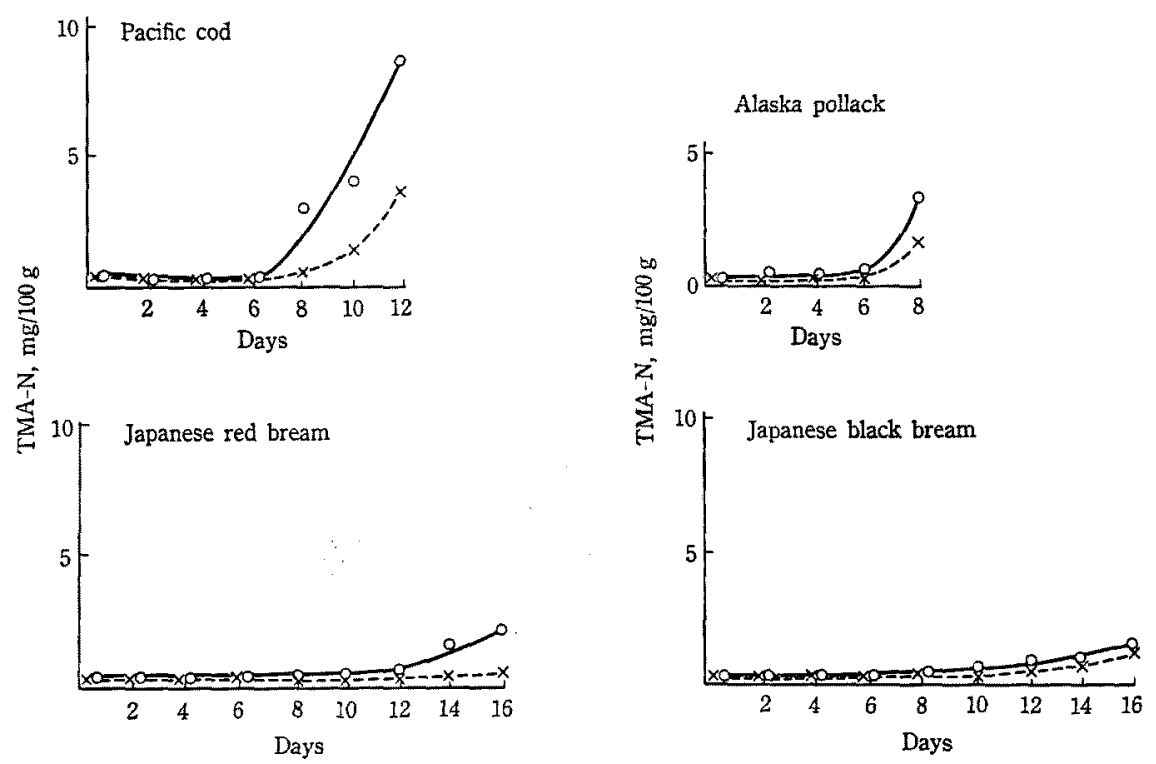

Fig. 5. Changes in the amount of trimethylamine (TMA)-N in the muscles of Pacific cod, Alaska pollack, Japanese red and black breams during ice storage. $\bigcirc-\circ$ : Determined by a ConwaY's method, $\times---\times$ : Determined by the picrate method. 
referring to the importance of the compound as the objective criterion for assessing quality of fish in international trade. However, as pointed out by SPINELLI et al. ${ }^{19)}$ the measurement of ATP related compounds provides much better information than does the bacterial metabolic end products regarding the quality of fish.

Changes in ATP related compounds in fish muscle Changes in ATP and its related compounds in muscle of the 4 species of fish during ice storage are shown in Fig. 6. Adenine nucleotides of all the species degraded rapidly within 1-2 days. However, the rate of IMP decomposition in fish muscle differed between species: IMP in muscle of both sea breams degraded very slowly, whereas that of both cods degraded rapidly. Fig. 7 shows their $\mathrm{K}$ values calculated from the measured values shown in Fig. $6 . \mathrm{K}$ values
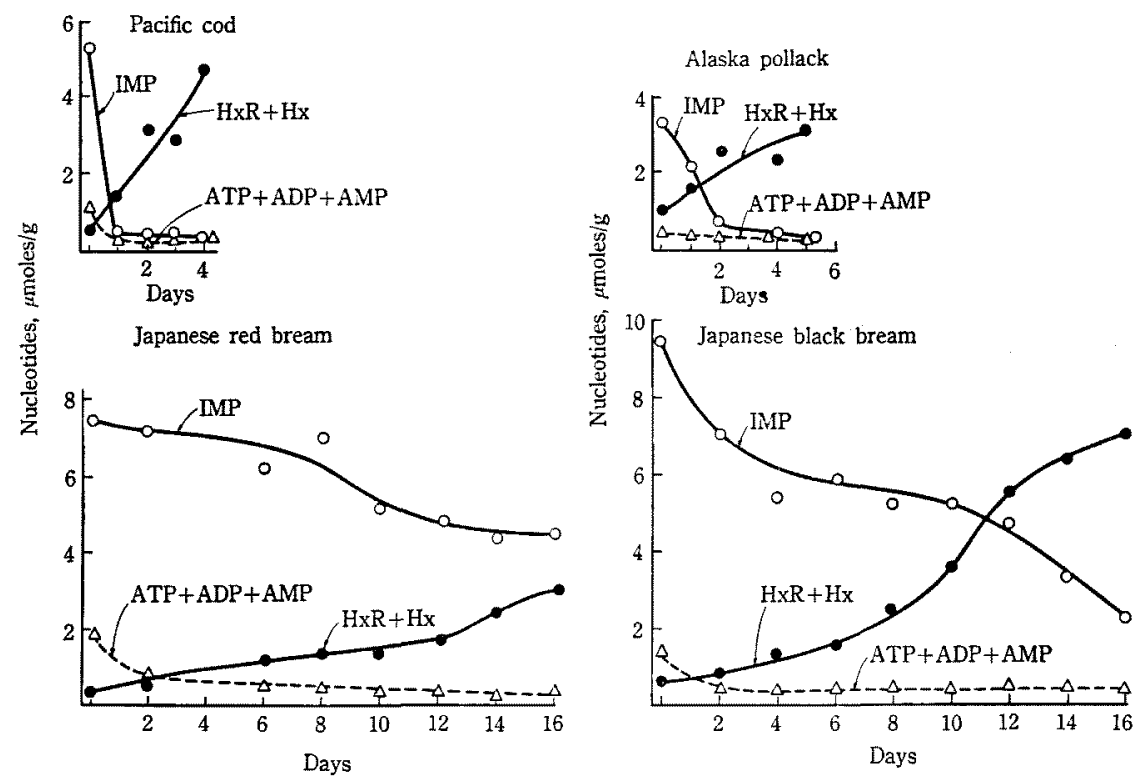

Fig. 6. Changes in the amount of ATP and its related compounds in the muscles of Pacific cod, Alaska pollack, Japanese red and black breams during ice storage.

of both cods increased up to $60 \%$ within two days of ice storage, whereas those of Japanese black bream and red bream $20 \%$ in 8 and 12 days of ice storage, respectively. In order to examine the upper limit of $\mathrm{K}$ value of fresh fish, we measured $\mathrm{K}$ values of tuna meat of good quality, "sushi dane" or sliced raw fish meat for rice ball ("sushi")," and the fish immediately after being landed at some local fishing ports, ${ }^{20)}$ and found the value to be around $20 \%$. Comparing these results with those shown in Fig. 7, it is clear that freshness of cod muscle lowered quite rapidly. The striking differences among species of the change in $\mathrm{K}$ value are considered to reflect well those of their freshness-lowering 


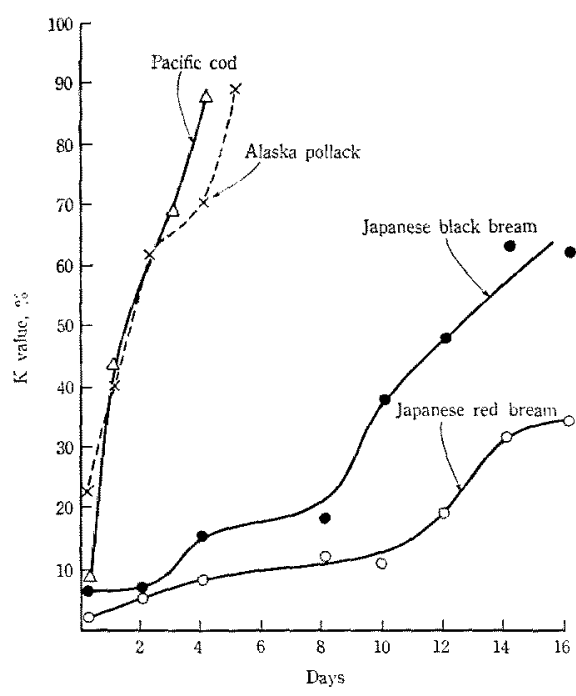

Fig. 7. Changes in $\mathrm{K}$ values of Pacific cod, Alaska pollack, Japanese red and black breams during ice storage.

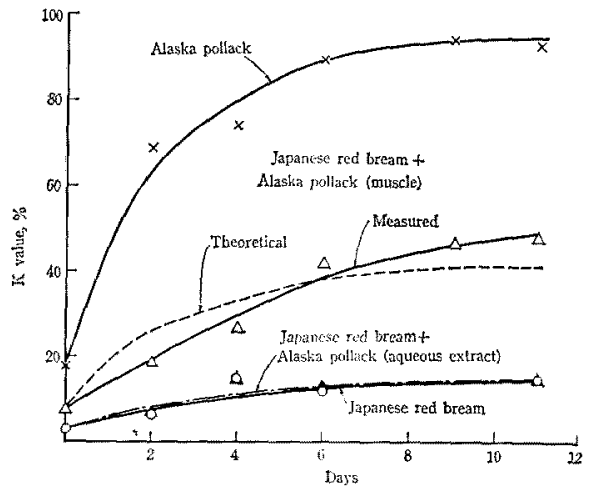

Fig. 8. Changes in $\mathbf{K}$ values of Japanese red bream muscle mixed with aqueous extract of Alaska pollack muscle, or the muscle itself, and mixed muscles of the two species during ice storage. Dotted line shows $\mathrm{K}$ value calculated theoretically (as described in the text) on the mixed muscles of the two species, assuming that the mixing of muscle of the different species has no effects on the decomposition of IMP in their muscle.

rates, which have been known experientially in the fishery circles in Japan as mentioned above. As shown in Fig. 6, it is clear that $\mathrm{K}$ value is influenced most strongly by IMP, so Japanese red bream muscle in which IMP decomposed slowly, was mixed with the aqueous extract of Alaska pollack muscle, or the muscle itself, whose IMP decomposed rapidly, homogenized, and the changes in $\mathrm{K}$ value of the homogenate during ice storage were examined. The results are shown in Fig. 8. As noted in the figure, $\mathrm{K}$ values of the homogenate of Japanese red bream muscle mixed with the aqueous extract of Alaska pollack muscle were in accord with those of Japanese red bream muscle itself throughout ice storage. And $\mathrm{K}$ values of the homogenate of Japanese red bream muscle mixed with Alaska pollack muscle showed intermediate values between the $K$ values of the two species. The dotted line in the figure shows $\mathrm{K}$ values calculated theoretically, assuming that the mixing of the muscles from both species has no interaction in respect of IMP decomposition, from the average total amount (Japanese red bream, $15.8 \mu$ moles per g; Alaska pollack, $8.1 \mu$ moles per g) of ATP related compounds in muscles of the two species. Measured values accorded fairly well with those calculated theoretically. Thus, the rate of IMP decomposition in Japanese red bream muscle in which IMP decomposed slowly, was accelerated little by mixing it with the aqueous extract of Alaska pollack muscle, or the muscle itself, whose IMP decomposed quite rapidly. These results seem to suggest that, in the early stage of post-mortem, regulatory organizations in fish muscle cell are still maintained. The remarkable differences among species of IMP 
decomposition rate might be concerned with the existent states of phosphatases or $5^{\prime}$ nucleotidases and IMP in muscle cell, or with the differences in activity of these enzymes. In order to clarify these points, a study on the intracellular distribution of the activities of these enzymes is now in progress.

\section{Acknowledgement}

The authors wish to express their heartiest thanks to Mr. Fumiaki UdA, Nomura Research Institute of Technology and Economics for his valuable advice and discussions given in the course of the present study.

\section{References}

1) T. Satto, K. Arai, and M. Matsuyoshi: This Bull., 24, 749-750 (1959).

2) H. Uchiyama, S. Ehrra, H. Kobayashi, and W. Shimizu: ibid., 36, 177-187 (1970).

3) H. UCHTYAMA and S. EHIRA: ibid., 36, 977-992 (A Review) (1970).

4) H. UChrYama: J. Food Hyg. Soc. Japan, 12, 267-276 (A Review) (1971).

5) S. Ehira, H. UchiYama, F. UdA, and H. MatsumiYa: This Bull., 36, 491-496 (1970).

6) S. Ehira and H. Uchiyama: Bull. Tokai Reg. Fish. Res. Lab., (75), 63-73 (1973).

7) N. R. JONEs: Analyst, 85, 111-115 (1960).

8) N. R. Jones, J. Murray, E. I. Livingston, and C. K. Murray： J. Sci. Fd. Agrc., 15, 763-774 (1964).

9) The Health and Welfare Ministry ed.: Shokuhin Eisei Kensa Shishin (Text for hygenic examination of food): 1 , (IV), 13-16 (1959).

10) Y. Hashmoto and T. OKaICH: This Bull, 23, 269-272 (1957).

11) Hitachi Manufac. Co. ed.: Instruction manual for model KLA-3B amino acid analyzer (in Japanese), Hitachi Manufac. Co., Tokyo, 1967, pp. 74-77.

12) B. O. Kassemsarn, B. Sanz Perez, J. Murray, and N. R. Jones: J. Food Sci., 28, 28-37 (1963).

13) H. L. A. TARr and M. Leroux: J. Fish. Res. Bd. Canada, 19, 519-520 (1962).

14) H. L. A. Tarr and M. Leroux: Can. J. Biochem. Physiol., 40, 571-589 (1962).

15) T. SHimizu and H. MATSUmTYA: Technol. Biol., 1, 225-235 (1970).

16) N. Kato, H. UchiYama, and F. Uda: This Bull., 39, 1039-1044 (1973).

17) Y. Maruyama: in "Biseibutsu Seirigaku" (Physiol. of Microorg.), (ed. by T. Uemura, H. Fukumi, and T. YANAGTTA), Asakura Shoten, Tokyo, 1960, pp. 42-153.

18) J. M. Shewan, D. M. Grbson, and C. K. MurRay: The FAO Tech. Conf, on Fish Inspect, and Quality Control, FIC/69/R/16, FAO, 1969, pp. 1-8.

19) J. Sptnelli, M. Eklund, and D. Mryauchi: J. Food Sci., 29, $710-714$ (1964).

20) S. Emria, N. Kato, and H. UchiYAMA：Bull. Tokai Reg. Fish. Res. Lab., (69), 107-123 (1972). 